\title{
BMC
}

Evolutionary Biology

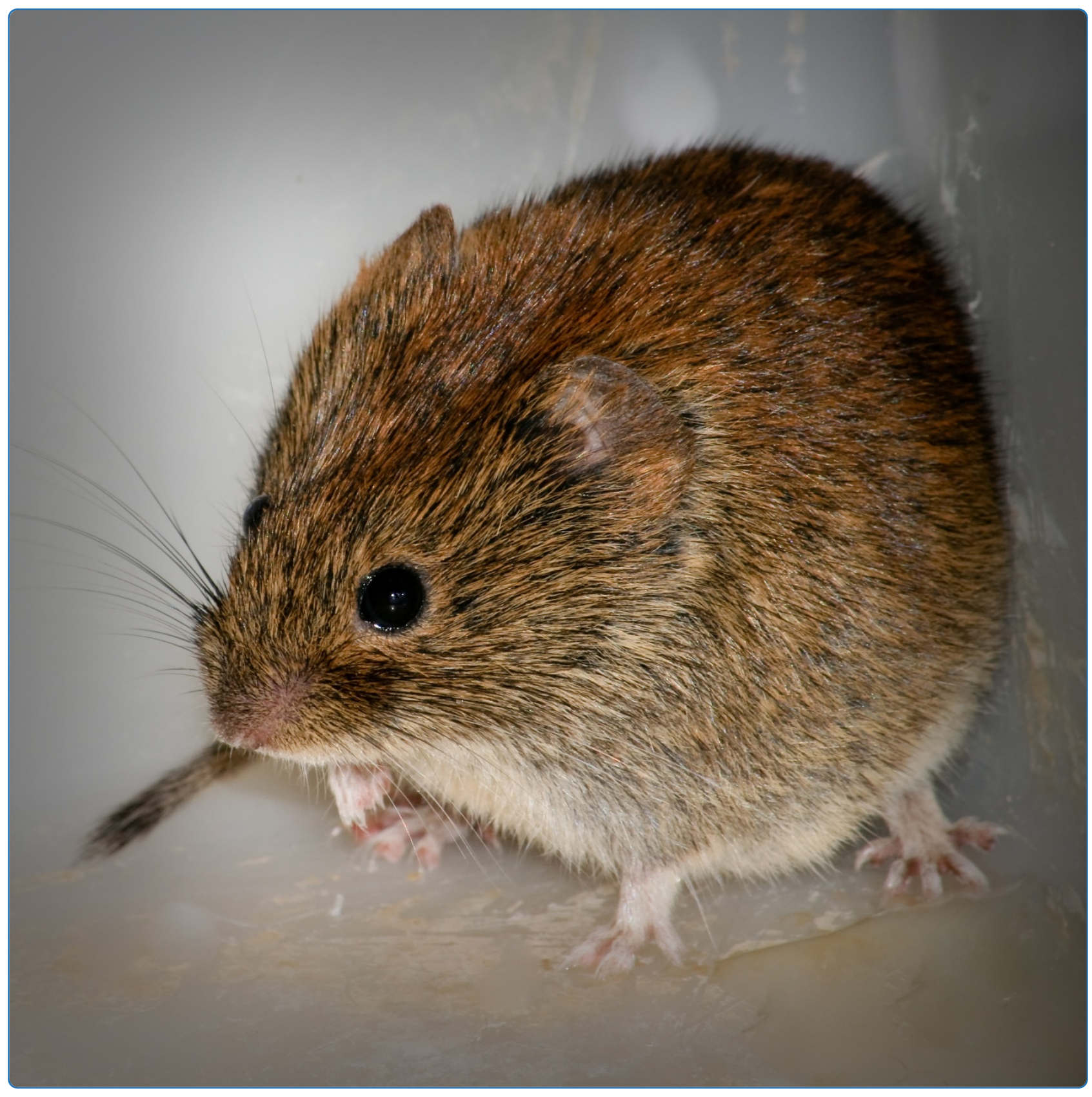

\section{Introgression of mitochondrial DNA among Myodes voles: consequences for energetics?}

Boratyński et al. 


\title{
Introgression of mitochondrial DNA among Myodes voles: consequences for energetics?
}

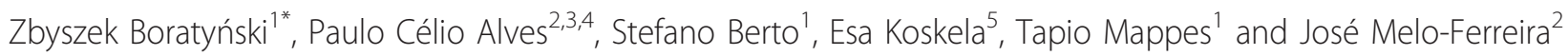

\begin{abstract}
Background: Introgression of mitochondrial DNA (mtDNA) is among the most frequently described cases of reticulate evolution. The tendency of mtDNA to cross interspecific barriers is somewhat counter-intuitive considering the key function of enzymes that it encodes in the oxidative-phosphorylation process, which could give rise to hybrid dysfunction. How mtDNA reticulation affects the evolution of metabolic functions is, however, uncertain. Here we investigated how morpho-physiological traits vary in natural populations of a common rodent (the bank vole, Myodes glareolus) and whether this variation could be associated with mtDNA introgression. First, we confirmed that M. glareolus harbour mtDNA introgressed from M. rutilus by analyzing mtDNA (cytochrome $b$, 954 bp) and nuclear DNA (four markers; 2333 bp in total) sequence variation and reconstructing loci phylogenies among six natural populations in Finland. We then studied geographic variation in body size and basal metabolic rate (BMR) among the populations of $M$. glareolus and tested its relationship with mtDNA type.
\end{abstract}

Results: Myodes glareolus and its arctic neighbour, M. rutilus, are reciprocally monophyletic at the analyzed nuclear DNA loci. In contrast, the two northernmost populations of $M$. glareolus have a fixed mitotype that is shared with M. rutilus, likely due to introgressive hybridization. The analyses of phenotypic traits revealed that the body mass and whole-body, but not mass corrected, BMR are significantly reduced in M. glareolus females from northern Finland that also have the introgressed mitotype. Restricting the analysis to the single population where the mitotypes coexist, the association of mtDNA type with whole-body BMR remained but those with mass corrected BMR and body mass did not. Mitochondrial sequence variation in the introgressed haplotypes is compatible with demographic growth of the populations, but may also be a result of positive selection.

Conclusion: Our results show that the phenotypic traits vary markedly along the north-south axis of populations of M. glareolus. This variation may be related to adaptation to local environments and coincides with the gradient of genome reticulation between $M$. glareolus and M. rutilus, which was assessed by mtDNA introgression. Introgression of mtDNA may have affected morpho-physiological traits but do not show strong effects on either body mass or basal metabolic rate alone. We discuss the causes and biological meaning of our results and the means to clarify these questions in future research.

\section{Background}

Widely distributed species face different selection pressures along climatic and ecological gradients. In this respect, basal metabolic rate (BMR) is particularly prone to evolve adaptively, since it has been shown to be heritable and correlates with fitness components in endotherms [1-8]. Several comparative studies have proposed that patterns of variation in metabolic rate match

\footnotetext{
* Correspondence: boratyns@gmail.com

${ }^{1}$ Centre of Excellence in Evolutionary Research, Department of Biological and Environmental Science, University of Jyväskylä, P.O. Box 35 YAC, Finland Full list of author information is available at the end of the article
}

certain climatic variables in widely distributed groups of species $[9,10]$, suggesting that the level of BMR responds to different selection regimes generated by local conditions. BMR is generated mainly in physiologically important internal organs including the kidneys, brain and liver $[11,12]$ with most of the physiological activity localized in certain compartments of cells in these organs.

Mitochondria are the main cellular energy "factories", supplying organisms with energy stored in ATP molecules. The rate of energy production by mitochondria is crucial for an individual's fitness and is thought to be determined by natural selection [13-15]. Mitochondria 
are characterized by their own genome and harbour enzymatic elements of aerobic metabolic pathways. However, oxidative phosphorylation (OXPHOS), the process responsible for energy production, depends not only on the enzymes encoded in the internal organelle genome (mitochondrial DNA [mtDNA]), but also on nuclear-encoded polypeptides which interact to enable the enzymatic reactions. Therefore, selection may act on and constrain the co-evolution of mitochondrial and nuclear genes [16]. Interestingly, between-species transfer of mtDNA has been frequently observed among many group of animals and plants [17-22]. Such transfer has been traditionally considered neutral, however, it may be maladaptive, if introgression breaks the coevolved mito-nuclear complexes [16], or adaptive, as mtDNA function may represent important selective value [23-26].

Interspecific mtDNA transfer observed among the broadly distributed rodent genus Myodes [27-30] offers an ideal situation to test 1 ) if reticulate evolution has an important and recognizable phenotypic effect and 2) whether natural selection may influence mtDNA introgression. The bank vole, Myodes glareolus, is dispersed across different climatic and geographic zones, from the Mediterranean to beyond the Arctic Circle [29,31] (Figure 1). The distribution of its close relative, the northern

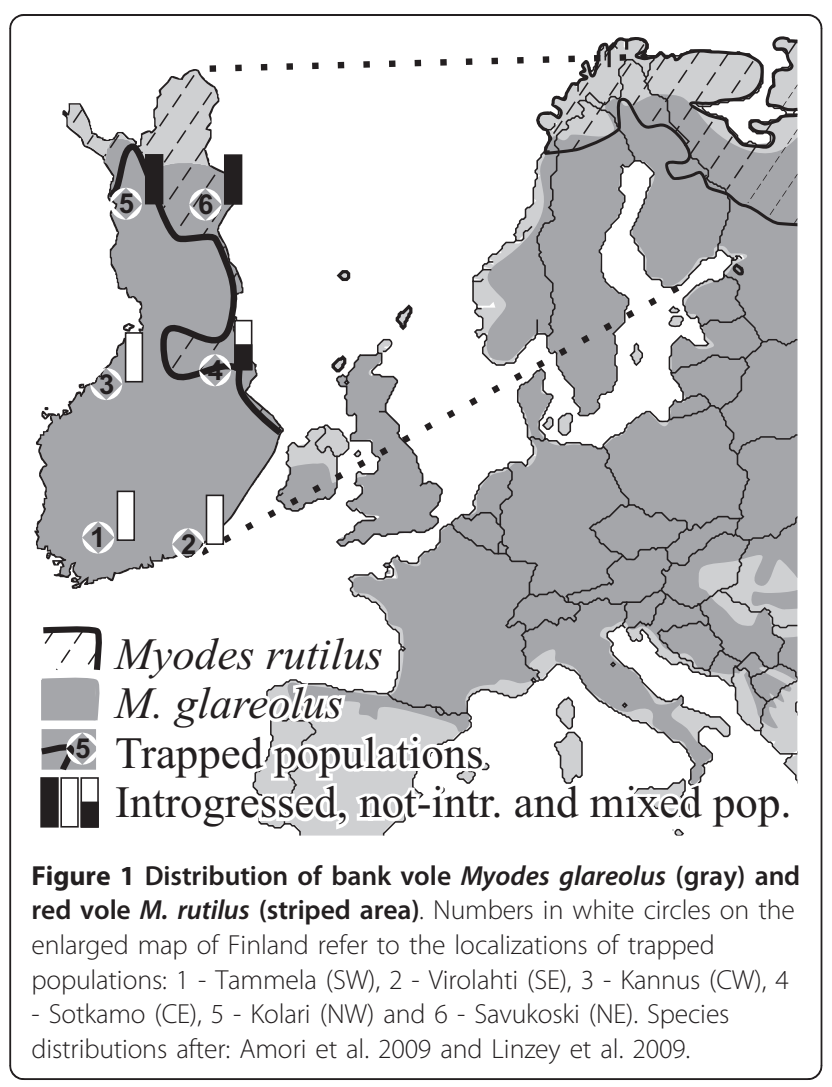

red-backed vole (or red vole), M. rutilus, is restricted to northern parts of the circum-boreal zone, extending to the Arctic zone [29,32]. The red vole occurs from northern Fennoscandia and northern Eurasia, where it is partly sympatric with the bank vole, to the northern latitudes in North America. Introgressive hybridization between the bank vole and the red vole has been documented across a vast geographic area, from Sweden to central and southern Russia [33,34] including northern Finland [27]. All these cases showed introgression of mtDNA alone and no introgression of the nuclear genome has been reported $[27,28]$.

In this work we revisited a geographic region where mtDNA introgression between M. glareolus and M. rutilus has been previously described [27]. First, using sequence data both from mtDNA and nuclear DNA, we confirm that mtDNA introgression from $M$. rutilus into M. glareolus occurs naturally in Finland, with the introgressed haplotype being fixed in the northernmost populations. Since the mitochondria house the energy machinery of the cells, we analyzed variation in two morpho-physiological traits (body size and basal metabolic rate) among $M$. glareolus populations, and found differences between females from populations with different mtDNA types, although the effect of geography could not be excluded. The underpinnings and consequences of this variation are discussed.

\section{Results}

\section{Genetic variation}

In total, 201 voles trapped during summer 2008 in 6 localities in Finland (Figure 1) were analyzed for variation in mitochondrial and nuclear markers (Additional file 1: Table S1, Additional file 2: Table S2, Additional file 3: Table S3, Additional file 4: Table S4 and Additional File 5; Accession numbers: [GenBank: JF929975JF930131]). After allelic phase determination (number of removed haplotypes per gene, with a lower probability of 0.95 , for LCAT, G6pd, BRCA1 and GHR were 1, 0, 0 and 5 , respectively) the number of alleles present in $M$. glareolus nuclear genes varied between 7 and 10 (Table 1 ). The phylogenies reconstructed for each of the nuclear genes were consistent across methods and coincided with the expected assignment of individuals to the species (Figure 2), since both M. glareolus and M. rutilus (see geographic distribution in Figure 1) were recovered as monophyletic with high statistical support (Figure 2). The cyt $b$ sequences obtained were most likely of mitochondrial origin and not of nuclear integrated copies, as the reading frame was unbroken (no stop codons were found) and the composition of the third codon position was typical (A 40.5\%, C $39.4 \%$, G $2.2 \%$ and $\mathrm{T} 17.8 \%$ ) compared to the average in mammals (A 39\%, C 36\%, G 3\% and T 21\%; [35]). 
Table 1 Sequence diversity and neutrality tests for nuclear markers of bank voles.

\begin{tabular}{lcccccccc}
\hline Gene & $\boldsymbol{n}_{\boldsymbol{i}}$ & $\boldsymbol{n}_{\boldsymbol{h}}$ & $\boldsymbol{n}_{\boldsymbol{p}}$ & $\boldsymbol{h}$ & $\boldsymbol{\pi}(\%)$ & $\boldsymbol{\Theta}_{(\boldsymbol{s})}$ per site (\%) & Tajima's $\boldsymbol{D}$ & Fu's $\boldsymbol{F}_{\boldsymbol{s}}$ \\
\hline LCAT & 386 & 8 & 6 & $.51(.02)$ & $.15(.12)$ & $.16(.07)$ & -15 & -1.43 \\
G6pd & 388 & 7 & 6 & $.08(.02)$ & $.01(.03)$ & $.16(.07)$ & $-1.72^{\&}$ & $-11.66^{*}$ \\
BRCA1 & 388 & 8 & 7 & $.48(.02)$ & $.09(.08)$ & $.19(.08)$ & -1.05 & -3.62 \\
GHR & 376 & 10 & 11 & $.74(.02)$ & $.36(.22)$ & $.27(.10)$ & .72 & 2.23 \\
\hline
\end{tabular}

$n_{i}$, number of sampled chromosomes; $n_{h}$, number of haplotypes; $n_{p}$, number of polymorphic sites; $h$, haplotype diversity; $\pi$, nucleotide diversity; $\Theta_{(S)}$, computed from the number of segregating sites. Standard deviations are shown in brackets. \&and * indicate $p<0.05$ and $<0.001$, respectively.

Polymorphism was found in 124 sites (137 when including Swedish population and individuals trapped in 2009 in Central East Finland) which defined 81 haplotypes (99 when including Swedish and 2009 individuals) within M. glareolus (Table 2). Contrary to inferences based on the sequences of the four nuclear genes, the cyt $b$ haplotypes sampled in M. glareolus did not form a monophyletic clade, and was instead split into two clades, only partially overlapping with species assignment. One clade, the $M$. rutilus-type mtDNA (RUT),

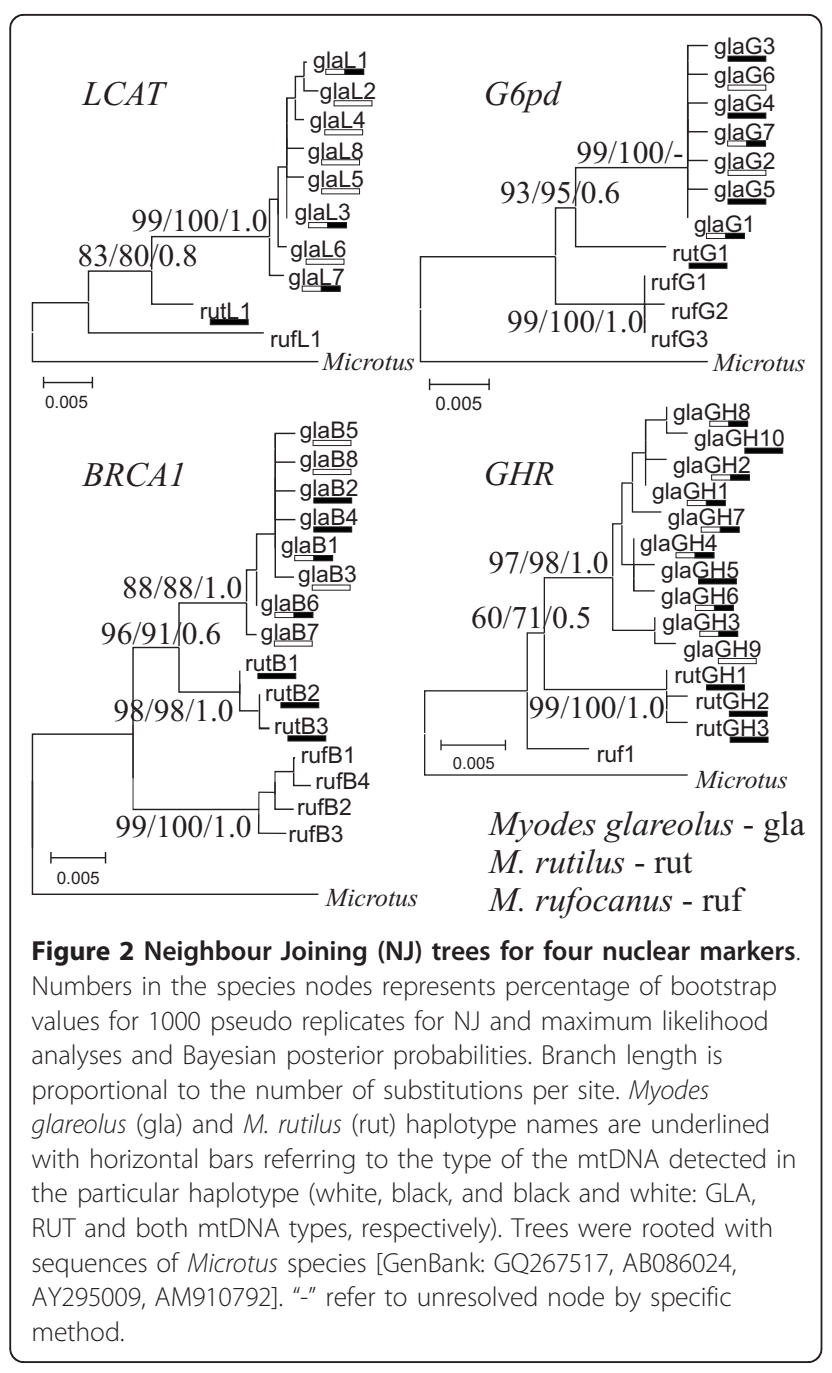

grouped 57 (65 when including Swedish and specimens sampled 2009) individuals of M. glareolus together with $M$. rutilus specimens, suggesting mtDNA introgression. The second clade, M. glareolus-type mtDNA (GLA), only grouped haplotypes specific for M. glareolus (Figure $3)$. The geographic distribution of each of these haplogroups was partly disjoint, with Southern and Central Finland (1-4 on Figure 1) being occupied by the GLA type mtDNA, whereas the North and Central-East (4-6) populations had the RUT type. One population located in Central-Eastern Finland exhibited both mitotypes (population 4: Figure 1).

Nuclear DNA sequence variation within $M$. glareolus was also detected (Table 1). The frequency spectrum of mutations did not significantly differ from the neutral mutation-drift expectations for most genes, as determined by Tajima's D and Fu's Fs (Table 1). For cyt $b$, sequence diversity of individuals with the GLA and RUT mitotype was comparable and high (Table 2). GLA and RUT type cyt $b$ sequences differed by 0.098 (0.014) and 0.102 (0.014) substitutions per site, respectively, from $M$. rufocanus sequences, while the divergence between GLA and RUT mitotypes was 0.070 (0.011) (net between group average distances and its standard errors calculated by bootstrapping 1000 times). The mismatch analysis of $c y t b$ sequences from $M$. glareolus showed a bimodal distribution of the number of pairwise differences (Figure 4a), which illustrates the existence of two divergent lineages. Similar results were obtained for the population from East-Central Finland (population 4, Sotkamo; Additional file 6: Figure S1d), where the mtDNA lineages coexist. The mismatch distributions analyzed separately for each of the mtDNA type (Figures $4 \mathrm{~b}$ and $4 \mathrm{c}$ ) and population were unimodal (Additional file 6: Figure S1). The goodness of fit test for deviation from the expectation under the Sudden Expansion Model rejected the model for the data set including all bank voles with their own mtDNA (Figure $3 \mathrm{~b}$; $\mathrm{p}=$ 0.019). All significant Tajima's $D$ and Fu's $F_{s}$ values were negative (Table 2). Both the unimodality of the $c y t b$ mismatch distribution within clades/populations and negative and significant values of tests of selective neutrality are expected for populations undergoing recent demographic growth or/and under positive selection. 
Table 2 Sequence diversity and neutrality tests for cyt $b$ of bank voles with different mtDNA types (GLA, RUT) and from different populations (see map: Figure 1).

\begin{tabular}{|c|c|c|c|c|c|c|c|c|}
\hline & $n_{i}$ & $n_{h}$ & $n_{p}$ & $h$ & $\pi(\%)$ & $\boldsymbol{\Theta}_{(S)}$ per site $(\%)$ & Tajima's $D$ & Fu's $F_{s}$ \\
\hline All data & 201 & 81 & 124 & $.97(.01)$ & $3.28(1.59)$ & $2.11(.51)$ & 1.50 & -6.13 \\
\hline GLA type mtDNA & 144 & 57 & 65 & $.95(.01)$ & $.28(.17)$ & $1.23(.31)$ & $-2.39 *$ & $-26.64^{*}$ \\
\hline RUT type mtDNA & 57 & 24 & 29 & $.95(.01)$ & $.37(.21)$ & $.66(.21)$ & $-1.42^{+}$ & $-12.51^{*}$ \\
\hline \multicolumn{9}{|c|}{ population/mtDNA type } \\
\hline Sweden/GLA & 10 & 6 & 9 & $.89(.07)$ & $.31(.20)$ & $.33(.17)$ & -.37 & -.88 \\
\hline SW/GLA & 34 & 14 & 20 & $.87(.04)$ & $.19(.13)$ & $.51(.19)$ & $-2.12^{*}$ & $-8.34^{\&}$ \\
\hline SE/GLA & 35 & 8 & 9 & $.75(.06)$ & $.14(.10)$ & $.23(.10)$ & -1.15 & -2.42 \\
\hline CW/GLA & 43 & 23 & 27 & $.96(.01)$ & $.31(.19)$ & $.65(.22)$ & $-1.76^{*}$ & $-16.49^{\&}$ \\
\hline CE/GLA, RUT & 102 & 30 & 94 & $.94(.01)$ & $2.32(1.14)$ & $1.90(.49)$ & .73 & 3.94 \\
\hline CE/GLA & 85 & 23 & 28 & $.92(.02)$ & $.29(.17)$ & $.59(.18)$ & $-1.54^{*}$ & $-11.02^{\&}$ \\
\hline CE/RUT & 17 & 7 & 7 & $.83(.06)$ & $.26(.17)$ & $.22(.11)$ & .72 & -.90 \\
\hline NW/RUT & 33 & 12 & 14 & $.89(.03)$ & $.28(.17)$ & $.36(.14)$ & -.70 & $-3.37^{+}$ \\
\hline NE/RUT & 15 & 9 & 17 & $.92(.04)$ & $.44(.26)$ & $.55(.23)$ & -.77 & -1.63 \\
\hline
\end{tabular}

$n_{i}$, number of individuals; $n_{h}$, number of mtDNA haplotypes; $n_{p}$, number of polymorphic sites; $h$, haplotypes diversity; $\pi$, nucleotide diversity; $\Theta_{(S)}$, computed from the number of segregating sites. Standard deviations are shown in brackets. ${ }^{+},{ }^{*}$ and ${ }^{*}$ indicate $p<0.055,<0.05$ and $<0.001$, respectively.

Given the average rate of cytochrome b divergence for rodents [36] of $0.176 \%$ per site per Myr and the parameters derived from the mismatch distribution $(\tau=3.5$; $\mathrm{CI}=1.9-4.7)$ for the introgressed haplogroup, this translates to an expansion time of approximately10 500 (5 500-14 000) years ago. The unimodal distribution and star-like network may imply that introgression of mtDNA happened only once into the Finnish populations of bank voles (Figure 3). Despite the excess of rare alleles that were generally detected in $M$. glareolus in the $c y t b$ and not in the nuclear genes, the multilocus HKA test [37] did not reject the null neutral model of evolution ( $p>0.05)$.

\section{Phenotypic variation}

All traits measured were positively correlated $(\mathrm{N}=$ 191, $\mathrm{r}=0.66,0.57$ and 0.43 for BMR-BM, HW-BM and BMR-HW; $\mathrm{p}<0.001)$ and all repeatability estimates (coefficients of intraclass correlation) were high and statistically significant $(\tau>0.62, \mathrm{p}<0.0003$, Table $3)$. As body mass and BMR were significantly influenced by a latitude-sex interaction in the initial analyses of variance $(\operatorname{logBM}: \mathrm{F}=3.13, \mathrm{p}=0.046, \operatorname{logBMR}$ : $\mathrm{F}=3.41, \mathrm{p}=0.035$, Additional file 7: Figure S2), further tests were performed separately within sexes. Whole body BMR was higher in the GLA than in the RUT mitotype in $M$. glareolus females ( $\mathrm{p}=0.032$; Table 4, Figure 5a). For males, whole body and masscorrected BMR decreased toward the North $(\mathrm{p}=0.002$ and 0.015 ) but did not differ between mitotypes (the effect was generated mainly by Southern populations, which had the highest values of BMR, Additional file 7: Figure S2). Female M. glareolus with the GLA mitotype were significantly heavier than females with the RUT mitotype ( $p=0.004$, Figure $5 \mathrm{~b})$. Longitude, latitude and their interaction did not affect variation in females' body mass and were sequentially excluded from the model $(\mathrm{p}>0.1)$. Within the sympatric population of two mitotypes (Figure 1; population 4), 8 females and 8 males of $M$. glareolus were detected with $M$. rutilus mtDNA (Table 4). The introgressed females had significantly lower values of whole-body BMR than sympatric females with native mtDNA ( $\mathrm{p}=$ 0.049, Figure 5a). Mass corrected BMR showed the same trend but was not significant $(p=0.262)$. These effects were also similar for males and in the same direction, but were also insignificant. No significant differences between sympatric mitotypes in body mass were detected in this population (Table 4; Figure 4b).

\section{Discussion}

Although mitochondria serve important physiological functions in organisms, its evolution has traditionally been considered neutral. Accordingly, mtDNA variation should have little phenotypic consequences in natural populations [26]. However, during the last decade evidence is accumulating that the evolution of mtDNA is often subject to natural selection [38,39]. Over 20 years ago, mtDNA flow between two species of Myodes voles, the bank vole, Myodes glareolus, and the red vole, $M$. rutilus, was first described [27], providing a potentially good model to test whether naturally occurring mtDNA introgression may influence phenotypic traits. Here, in addition to sampling some $M$. rutilus specimens, we sampled $M$. glareolus in 6 Finnish populations, including the northern range of the species where it overlaps with $M$. rutilus, where mtDNA introgression might occur. We assessed mtDNA introgression by comparing the mtDNA-based phylogeny with that of 4 nuclear DNA markers. As expected, we detected congruence between 


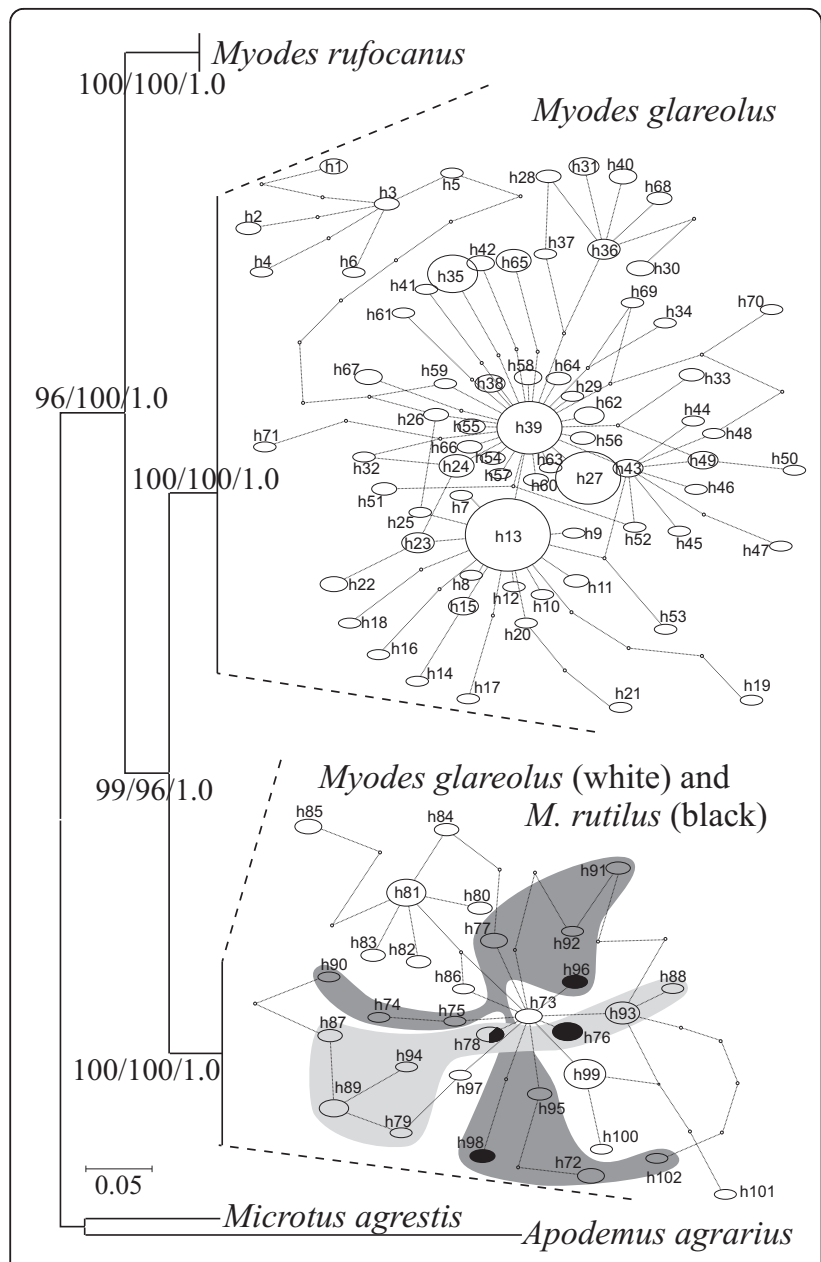

Figure 3 Neighbour Joining (NJ) trees for cytochrome b. Numbers in the species nodes represents percentage of bootstrap values for 1000 pseudo replicates for NJ and maximum likelihood analyses and Bayesian posterior probabilities. For simplicity the tree is collapsed into the major clades. Branch length is proportional to the number of substitutions per site. Haplotype networks for mtDNA of native (GLA) and introgressed Myodes glareolus (RUT) together with $M$. rutilus are presented separately. Oval sizes are proportional to the number of sampled individuals. Points on the branches indicate hypothetical haplotypes. Shadings for the introgressed haplotypes refer to populations: light gray - 4, Sotkamo (CE), dark gray - 6, Savukoski (NE), no shading - 5, Kolari (NW). Trees were rooted with sequences downloaded from GenBank (Microtus agrestis and Apodemus agrarius, AY167187 and AB303226).

species assignment of the individual voles with the variation in four nuclear markers (Figure 2), and found that most of the mtDNA haplotypes sampled in $M$. glareolus from northern Finland (Figure 1) cluster within the clade of $M$. rutilus (Figure 3), which is a typical consequence of mtDNA introgression [18-21,23]. Indeed, it is striking to note that the mtDNA haplotypes from $M$. rutilus are fixed in the northern populations of M. glareolus and only in one population did we find both the native and the introgressed mitotypes (Figure 1).

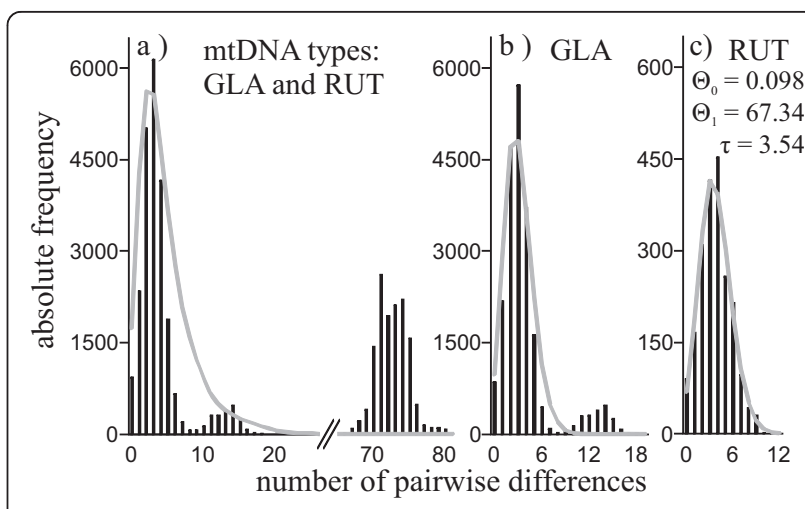

Figure 4 Observed (black bars) and expected (gray lines) mismatch distributions. Figures include: a) all samples of bank voles, Myodes glareolus, b) bank voles with native mtDNA type (GLA) and c) bank voles with mtDNA type of red voles M. rutilus (RUT).

Values of the expansion parameters are only shown if the assumptions of the Sudden Expansion Model are fulfilled (unimodal distribution and goodness of fit test: $p>0.05$ ).

Having identified among the sampled specimens those with native and introgressed mtDNA, we aimed to test whether introgression explains differences in two key phenotypic measures: body size and basal metabolic rate. These traits were studied because size and energetic physiology are important predictors for life history traits in animals $[8,12,40]$. Also, some of the most recent data and theoretical predictions link variation in those traits with different fitness components $[1,2,6]$. We found that the repeatability of size and metabolism was significant (Table 3) and that phenotypes varied markedly between distantly located populations of bank voles. It has been postulated that the geographic variation in morpho-physiological traits might be caused by climatic differences among distant localities [10,41]. If so, the phenotypic differences are predicted to be noticeable and caused by phenotypic plasticity or adaptation to different habitats along environmental gradients, which here could include information inherited in mtDNA as a possible mechanism of physiological adaptation [42].

Table 3 Repeatabilities of body mass, head width and basal metabolic rate.

\begin{tabular}{lcccccc}
\hline & \multicolumn{3}{c}{ ANOVA } & \multicolumn{4}{c}{ ANCOVA (with BM) } \\
Trait & $\mathbf{N}$ & $\boldsymbol{\tau}$ & $\mathbf{p}$ & $\mathbf{N}$ & $\boldsymbol{\tau}$ & $\mathbf{p}$ \\
\hline $\log B M$ & 26 & .87 & $<.0001$ & 26 & & \\
$\log H W$ & 25 & .83 & $<.0001$ & 25 & .74 & $<.0001$ \\
$\log B M R$ & 26 & .80 & $<.0001$ & 26 & .62 & $<.0003$
\end{tabular}

$\tau$, coefficient of intraclass correlation based on two repeated measurements across in average 35.5 days ( $\min 16, \max 51$ ), based on variance components from ANOVA with study individual as categorical predictors, or from ANCOVA with body mass included as covariate (which provides repeatability of massindependent trait values). 
An interesting observation from our results is that the northern (and introgressed) Myodes glareolus voles were smaller and had lower BMR values than voles from the southern populations (and with the native mitotype, Additional file 7: Figure S2). Sex specific tests showed that females with different mtDNA types differed in body mass and absolute (whole-body) metabolic rate but not in mass-corrected BMR, whereas males from northern populations had lower values of absolute and masscorrected BMR, but not body mass, and their traits did not vary significantly between mtDNA types (Table 4). Whether the inferred differences across populations are due to mtDNA introgression or related to genome reticulation is difficult to assess because bank voles from northern populations are also exclusively introgressed. To circumvent this problem we analyzed a subsample of the data from the single population where both mitotypes coexist, thus eliminating the geographic factor. Although we did not find a significant difference in body size between introgressed and non-introgressed voles (Figure $5 \mathrm{~b}$ ), we found that introgressed females had lower absolute BMR values than non-introgressed ones (Table 4, Figure 5a). However, this association was not significant when BMR was mass-corrected. Though, only 8 females with $M$. rutilus mtDNA type were sampled in this population, which yields little power to detect effects on body size and mass corrected BMR. The absence of a strong relationship between mtDNA type and variation in phenotypic characters could have resulted from relatively recent divergence between vole species, and consequently, the functional similarity between mitochondrial and nuclear genes, as shown in recent experimental transitions of whole genomes in Drosophila species [43]. Otherwise, the co-introgression of some nuclear genes that have not been included in current analyses, but may be important for energetic physiology and body growth rate, may have balanced the incompatibility and influenced particular phenotypes $[44,45]$. The observed sex-specific effects of mtDNA on phenotypes, visible at least in the between-population analyses carried out here and in another study [46], could be explained by different requirements between sexes connected to their reproductive biology $[8,47]$. In fact, recent models predict e.g. that the level of the rate of basal metabolism in endotherms is a consequence of directional selection operating on reproductive performance $[48,49]$. Accordingly, such processes are related to two energetically-costly female reproductive processes: pregnancy and lactation. It has been also experimentally confirmed that directional selection can perform differentially on size and metabolic rate between sexes in mammals [1,2]. However, the most important prediction for differential effects of mtDNA on phenotype comes from the fact that in mammals, mitochondria are almost exclusively transmitted through females. Consequently, mtDNA can only have direct adaptive effect for females and the mtDNA effects on male phenotype are expected to result from counterbalancing effects of nuclear genes [50].

The prevalence of the introgressed mtDNA haplotype in the northern populations of $M$. glareolus in extreme frequencies - the foreign haplotype seems fixed in these populations - is striking, and we thus raised the hypothesis that mtDNA introgression could have been

Table 4 Phenotypic differences between bank voles with different mtDNA types.

\begin{tabular}{|c|c|c|c|c|c|c|c|c|c|c|c|}
\hline \multirow[b]{4}{*}{ Traits } & \multicolumn{6}{|c|}{ All populations } & \multicolumn{5}{|c|}{ Sympatric population } \\
\hline & \multirow{2}{*}{\multicolumn{2}{|c|}{ Myodes rutilus }} & \multicolumn{4}{|c|}{ itochondrial DNA type of } & \multicolumn{4}{|c|}{ mitochondrial DNA type of } & \multirow{3}{*}{$\frac{\mathrm{mtDN} /}{\mathrm{p}}$} \\
\hline & & & \multicolumn{2}{|c|}{ M. glareolus } & \multirow{2}{*}{$\frac{\mathrm{mtDNA}}{\mathrm{p}}$} & \multirow{2}{*}{$\begin{array}{c}\text { lat. } \\
p\end{array}$} & \multicolumn{2}{|c|}{ Myodes rutilus } & \multicolumn{2}{|c|}{ M. glareolus } & \\
\hline & $\mathrm{N}$ & mean(SD) & $\mathrm{N}$ & mean(SD) & & & $\mathrm{N}$ & mean(SD) & $\mathrm{N}$ & mean & \\
\hline \multicolumn{12}{|l|}{ Females } \\
\hline BM & 20 & $16.7(2.72)$ & 63 & 19.4(3.84) & $.004^{*}$ & - & 8 & $16.8(2.77)$ & 29 & $19.7(4.56)$ & .098 \\
\hline HW & & 13.2(.370) & & 13.3(.370) & .163 & - & & 13.1(.395) & & 13.2(.426) & .317 \\
\hline & AR $\mathrm{R}_{\text {ANOVA }}$ & $40.1(4.12)$ & & $43.7(6.80)$ & .032 & - & & $39.3(4.16)$ & & $44.4(8.47)$ & .049 \\
\hline BM & $R_{\text {ANCOVA }}$ & $42.6(4.86)$ & & $42.9(4.73)$ & - & .445 & & $-.351(1.17)$ & & $.097(.928)$ & .262 \\
\hline \multicolumn{12}{|l|}{ Males } \\
\hline BM & 37 & 21.6(4.79) & 71 & $21.9(4.23)$ & - & .135 & 8 & 19.8(4.41) & 47 & $21.4(4.35)$ & .329 \\
\hline HW & & 13.4(.450) & & $13.4(.420)$ & - & .265 & & 13.2(.522) & & $13.4(.411)$ & .189 \\
\hline & AR $\mathrm{R}_{\text {ANOVA }}$ & 48.6(8.99) & & $49.0(11.67)$ & - & $.002^{*}$ & & $39.4(5.68)$ & & $45.1(9.12)$ & .374 \\
\hline BM & $R_{\text {ANCOVA }}$ & $48.9(8.80)$ & & $48.9(8.83)$ & - & $.014^{*}$ & & $-.124(.761)$ & & $.021(1.03)$ & .705 \\
\hline
\end{tabular}

Variation in body mass (BM, g), head width (HW, mm) and basal metabolic rate (BMR, $\mathrm{ml} \mathrm{O2} \mathrm{min-1)} \mathrm{is} \mathrm{presented} \mathrm{for} \mathrm{bank} \mathrm{voles} \mathrm{from} \mathrm{"all} \mathrm{populations"} \mathrm{and} \mathrm{from}$ Sotkamo "Sympatric population" where mitotypes coexist. Significance of the effects: type of the mtDNA (rutilus vs. glareolus), latitude (lat.) and longitude (insignificant and excluded from table) of population (6 populations) were tested in ANOVA or ANCOVA (for BMR with BM as covariate) models on log transformed traits as dependent variables. Marginal means (and their SDs) for mtDNA types for ANCOVA models were calculated accounting for variation in BM. The insignificant effects $(p>0.1)$ were hierarchically reduced from the analyses of variances "-" and are not presented in the table. Latitudexlongitude interactions affected only males log transformed and residual values of HW ( $p<0.045)$, not included in the table.

* effects significant after implemented Bonferroni correction. 


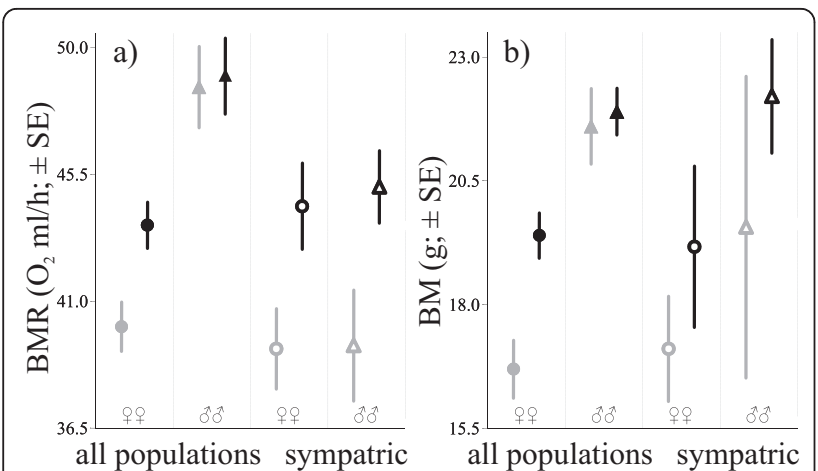

Figure 5 Differences in phenotype between mitotypes. Differences in means ( \pm SE) of a) basal metabolism (BMR) and b) body mass (BM), between native (black) and introgressed (gray) mtDNA types in Myodes glareolus. Data are presented separately for females (circles) and males (triangles) captured in allopatric (filled) or sympatric populations (open figures).

promoted by natural selection. We assessed if the frequency spectrum of mutations of the introgressed haplotypes could be biased towards an excess of rare alleles, a pattern compatible with post-introgression positive selection. Our analysis of sequence variation among the introgressed $c y t b$ haplotypes indeed shows a pattern that is not compatible with a model of population equilibrium (bell-shaped mismatch distribution and negative and significant Tajima's $D$ and Fu's $F_{s}$ values; Table 2). This could result from adaptive introgression of mtDNA, promoting the expansion of the novel haplotype northward. However, selection is expected to affect solely the locus in question, while the effect of population expansion and other demographic phenomena should affect the whole genome equally, on average. As the HKA test did not indicate any deviation from neutral expectations of the multilocus ratios of divergence to polymorphism (see Results) and both mitotypes identified in M. glareolus (GLA, and the introgressed RUT) showed similar expansion signals, our results suggest that the species itself may have undergone recent population expansion, spreading the traces of mtDNA introgression throughout the northern range of $M$. glareolus. Indeed, if hybridization occurs between a resident and an invading species, introgression is expected to occur into the spatially expanding one, in a stochastically neutral phenomenon [51,52]. This scenario has been used to explain massive mtDNA introgression among hares $[53,54]$ and (potentially) in other organisms [55]. In this demographic replacement process, markers with lower intraspecific migration rates, as is often the case with mtDNA, are expected to introgress more easily because the influx of native alleles into the invasion front is lower [51,52]. Thus, the northern expansion of M. glareolus into the range of $M$. rutilus could have favoured
mtDNA introgression in a purely neutral manner, and could also explain the asymmetry of the observed introgression. Such asymmetry could be explained by femalebiased assortative mating [56]. In a situation of interspecific contact with imbalanced frequencies of the interacting species, the females of the rare species (in this case, presumably the out-competed $M$. rutilus) tend to mate more easily with the heterospecific males, i.e., the expanding M. glareolus. The continuous backcrossing of hybrids with the same frequency-dependence over generations would cause introgression of the maternally transmitted mtDNA in the direction of the more abundant species ( $M$. glareolus). This asymmetry could also occur if the invasion of the range of M. rutilus by $M$. glareolus was pioneered by males, which are known to disperse farther than females in this species [57].

\section{Conclusion}

This study uncovered marked differences in body mass and BMR across Finnish populations of M. glareolus along a north-south axis. These differences correspond with massive mtDNA introgression from $M$. rutilus into the populations of $M$. glareolus, which suggests that genome reticulation may presumably be related to the differences in phenotype. Given its role in energy processing, mtDNA is an obvious candidate to underlie physiological phenotypic differences more directly. Although a signal of association between mtDNA introgression and whole-body BMR was detected from the analysis of the population where the native and foreign mtDNA haplotypes coexist, the results failed to show a relationship between mass-corrected BMR or body mass alone and the mitochondrial DNA. Further analyses using increased sample sizes and more populations where mtDNA types exist in sympatry will help to clarify this result. Also, the co-introgression of nuclear elements may be responsible for the altered phenotype and counterbalance eventual incompatibilities between nuclear and mitochondrial genomes. Obvious candidates for co-introgression with mtDNA are nuclear genes involved in physiological pathways, most notably those involved in mitochondrial function, which are known to co-evolve with mtDNA [16]. The construction of congenic strains in breeding experiments [58,59], where the mtDNA form $M$. rutilus is fixed in a nuclear background of M. glareolus, would allow testing if mtDNA alone alters phenotype, and ultimately, whether the mtDNA introgression has any significant fitness effects.

\section{Methods \\ Sampling}

Voles were trapped in six populations along NorthSouth and East-West gradients in Finland, near the towns of Tammela (SW Finland: $60^{\circ} 48^{\prime} \mathrm{N}: 23^{\circ} 58^{\prime} \mathrm{E}$ ), 
Virolahti (SE: $60^{\circ} 35^{\prime} \mathrm{N}: 27^{\circ} 34^{\prime} \mathrm{E}$ ), Kannus (CW: $63^{\circ}$

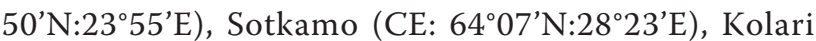
(NW: $67^{\circ} 19^{\prime} \mathrm{N}: 23^{\circ} 46^{\prime} \mathrm{E}$ ) and Savukoski (NE: $67^{\circ} 17^{\prime} \mathrm{N}: 28^{\circ}$ 09'E; Figure 1) in July and early of August 2008. Trappings were repeated during August 2009 in Sotkamo, where two mitotypes coexist in sympatry. Voles were trapped using 200 to 300 live traps in each population (Ugglan Special multiple-capture, Grahnab, Hillerstorp, Sweden). Several trap lines $(\geq 9)$ were distantly distributed from each other $(>2 \mathrm{~km})$ to lower the chance of trapping close relatives. Captured voles were assigned to species and individually marked with transponders (ID100, Trovan). These species are easily distinguishable since $M$. rutilus has a bright red back, which is much darker in $M$. glareolus, and the relative tail to body length differs greatly between the species [0.50 in $M$. glareolus and 0.25 in M. rutilus; [60]]. After capture (> 30 specimens per population) the voles were transported to the laboratory where they were housed in individual cages with wood shavings and hay as bedding, in a 16L:8D photoperiod and $20 \pm 2{ }^{\circ} \mathrm{C}$ with standard food (Labfor 36, Lactamin AB, Stockholm, Sweden) and water available ad libitum. The use of the animals adhered to ethical guidelines for animal research in Finland (permission numbers: ESLH-2008-04660/Ym-23 and ESLH-2009-09663/Ym-23) as well as all the institutional guidelines.

\section{Molecular laboratory procedures}

Genetic polymorphism in the mitochondrial cytochrome b (cyt b) and 4 nuclear genes (LCAT - lecithin-cholesterol acyltransferase exons 2 through 5, G6pd - Glucose-6-phosphate dehydrogenase partial intron, BRCA1 - Breast cancer 1 gene partial exon 11, GHR - growth hormone receptor partial exon 10) were analyzed for 264 voles trapped in 6 localities (including 53 voles trapped in 2009, Figure 1) in Finland and in one locality in Sweden (10 individuals). Additional reference sequences from these genes for Apodemus, Microtus and Myodes species were included [GenBank: GQ267517, AB086024, AY295009, AM910792, AY167187 and AB303226]. Total genomic DNA was extracted from ethanol preserved pieces of ear $\left(2-3 \mathrm{~mm}^{2}\right)$ collected during field expeditions using a Qiagen extraction protocol. Purification was conducted in a KingFisher apparatus. The $c y t b$ gene was amplified using primers specific to the bank vole (Additional file 1: Table S1) [33]. PCR reactions for cyt $b$ were performed in $30 \mu \mathrm{l}$ volume mixes containing $3 \mu \mathrm{l}$ of DNA, $0.24 \mu \mathrm{l}$ of Taq polymerase, $1.8 \mu \mathrm{l}$ of $\mathrm{F}$ and $\mathrm{R}$ primers $(5 \mu \mathrm{M}), 1.2 \mu \mathrm{l}$ of $\mathrm{MgCl} 2$ ( $2 \mathrm{mM}$ ), $3 \mu \mathrm{l}$ of dNTP, $3 \mu \mathrm{l}$ of reaction buffer and 15.96 $\mu \mathrm{l}$ of $\mathrm{H}_{2} \mathrm{O}$. Reactions for nuclear genes were performed on individuals trapped in 2008 in Finland as described above with following modifications including usage of
1X PCR buffer (BioTools), $200 \mu \mathrm{M}$ of dNTPs, $0.5 \mathrm{U}$ of Taq polymerase and optimum $\mathrm{MgCl} 2$ concentrations and specific primers (Additional file 1: Table S1). PCR reactions were performed using the following protocol: 3 min of preliminary activation of Taq polymerase at $95^{\circ} \mathrm{C}$ were followed by 32 ( 34 for nuclear genes) threestep cycles of denaturation at $94^{\circ} \mathrm{C}$ (30 sec), annealing temperature specific for primer $(30 \mathrm{sec}$; see Additional file 1: Table S1) and extension at $72^{\circ} \mathrm{C}(70 \mathrm{sec})$, and a final extension at $72^{\circ} \mathrm{C}(10 \mathrm{~min})$.

PCR products were purified by the Exo - SAP assay (Amersham Biosciences). Sequence analysis was performed with the BigDye Terminator v3.1 cycle sequencing kit (Applied Biosystems). Sequencing reactions were performed using the PCR primers (Additional file 1: Table S1) in $16 \mu \mathrm{l}$ mixes containing $1 \mu \mathrm{l}$ of primer $(3.3 \mu \mathrm{M})$ and $3 \mu \mathrm{l}$ of PCR product according to ABI sequencing protocol. Sequencing was conducted in two directions using a BigDye Terminator kit (Applied Biosystems) on an Applied Biosystems 3130xl Genetic Analyzer. Both forward and reverse strands were merged using the SeqScape v 2.1.1 and aligned using ClustalX v 2.0.10 softwares.

\section{Sequence analyses}

Initially, the allelic phase determinations for each of the nuclear gene were obtained with PHASE v2.1.1 [61]. In the subsequent phylogenetic analyses, only alleles with phase calls with posterior probabilities over 0.95 were used. DnaSP v 5.10 .01 [62] and ARLEQUIN 3.11 [63] were used to detect the number of haplotypes and number of variable sites within each gene and species. Phylogenetic relationships among sequences were reconstructed using three different methods. First, using the Neighbour Joining method, phylogenies were inferred from a distance matrix obtained with the JukesCantor nucleotide substitution model and the robustness of the trees were assessed by bootstrap resampling (BS: 1000 random replications) in MEGA 4 software [64]. Based on the reconstructed initial trees a hierarchical likelihood ratio test and AIC based model selection were then conducted in ModelTest v 3.0 [65], as implemented in HyPhy package [66] which determined the simplest model of sequence evolution that best fits variation in data. The chosen models were further included in the phylogenetic reconstructions. The robustness of Maximum-Likelihood phylogenetic analyses (ML) [67] was assessed by bootstrap resampling (1000 random replications) performed in the software PHYML v 2.4.4 [68]. The Bayesian inference (BI) approach was applied to reconstruct the phylogenies using the program MrBayes v 3.1.2 [69]. Four Markov Chain Monte Carlo (MCMC) simulations were started from the tree with random topology and branch lengths. Simulations were 
run for 10 million ( 1 million for nuclear markers) generations with trees sampled every 100 generations (100 000 trees saved) with the first 7000 (700 for nuclear markers) trees discarded from further analyses (burn-in). The remaining trees were used to construct the consensus tree and estimate posterior probabilities for all nodes in the $\mathrm{BI}$ tree using the $50 \%$ majority rule.

The relationships among $c y t b$ haplotypes were additionally analyzed and visualized with the statistical parsimony method implemented in TCS 1.21 [70]. These analyses were run together and separately for two types of mtDNA, bank vole - GLA and red vole - RUT (the latter group included haplotypes found both on bank voles and red vole specimens). We also estimated nucleotide diversity $(\pi), \theta_{\mathrm{s}}$ computed from number of segregating sites, haplotype diversity $(\mathrm{h})$ and mismatch distributions (ARLEQUIN 3.11) [63]. The mismatch distributions were calculated [71] and the goodness-of-fit tests of the observed to the expected distributions according to the Sudden Expansion Model were tested [72]. The Sudden Expansion Model assumes that initial population at equilibrium (of size: $\theta_{0}$ ) grew rapidly to a new size $\left(\theta_{1}\right)$, mutational times ago: $\tau=2 u t$ ( $\mathrm{u}-$ mutation rate, $\mathrm{t}$ - time since the expansion in generation). The confidence intervals for $\tau$ were calculated with 1000 bootstrap replicates for the alpha level of 0.010 . The assumption of selective neutrality and population equilibrium were tested with Tajima's D [73] and Fu's $F_{s}$ [74] statistics with 5000 simulated samples.

Multilocus ratios of polymorphism in M. glareolus to divergence between this species and $M$. rufocanus were contrasted with the expectations of a neutral model using a Hudson-Kreitman-Aguade (HKA) test [37] as implemented in the HKA program (http://lifesci.rutgers. edu/ heylab/).

\section{Metabolic measurements}

After two months of acclimatization to laboratory conditions, measurements of oxygen consumption $\left(\mathrm{ml} \mathrm{h}^{-1}\right)$ were conducted in an eight-channel open-flow respirometric system (Sable Systems, Henderson, NV) based on the Fc-1B $\mathrm{O}_{2}$ (Sable Systems) analyzer. The system was adapted to measure 7 animals (with the eighth channel as a reference) per day. Prior to measurements, animals were weighed and placed in Plexiglas chambers $(180 \mathrm{ml})$ without water or food at $30.0 \pm 0.5^{\circ} \mathrm{C}$, which is within the species thermal neutral zone. The chambers were connected to a system of dry air flow (after passing through a column with silica gel) of approximately $260 \mathrm{ml} \mathrm{min}^{-1}$ (accurate flows were measured with FlowBar, Sable Systems, Henderson, NV, and included in metabolic rate calculations). Oxygen consumption was recorded for a period of $7 \mathrm{~h} 30 \mathrm{~min}$ (from 09:00 to
16:30). The samples of dried air (passed through Drierite desiccant) were taken sequentially from the seven occupied measurement chambers and the reference chamber every $15 \mathrm{~min}$ (with flow rate: $150 \mathrm{ml} \mathrm{min}^{-1}$ ). In each cycle, each measurement chamber was active for at least 110 seconds (first and reference chambers were active $10 \mathrm{sec}$ longer each) during which $\mathrm{O}_{2}$ values were sampled every $1 \mathrm{sec}$. From each chamber, measurements taken during the last 20 seconds were used for the calculation of average oxygen consumption. Oxygen consumption (metabolic rate) was calculated using $\mathrm{O}_{2}$ measures according to the formula $\mathrm{VO}_{2}=\left\{\mathrm{V}_{\mathrm{i}}\right.$ $\left.\left(\mathrm{FdO}_{2}\right) /\left[1-\mathrm{FeO}_{2}(1-\mathrm{RQ})\right]\right\}$, [equation 1b from [75]] where $\mathrm{VO}_{2}$ is the oxygen consumption rate, $\mathrm{V}_{\mathrm{i}}$ is the flow rate measured before measurement chamber, $\mathrm{FdO}_{2}$ is the difference of $\mathrm{O}_{2}$ fractional concentrations in dry air flow before and after passing through the measurement chamber, and $\mathrm{FeO}_{2}$ is the fractional concentration of $\mathrm{O}_{2}$ in dry air flow after passing the measurement chamber. A respiratory quotient $\left(\mathrm{RQ}=\mathrm{CO}_{2}\right.$ eliminated/ $\mathrm{O}_{2}$ consumed) of 0.75 for nearly starved animals was assumed in the equation [75]. A total of 29 oxygen consumption values were calculated for each animal throughout one measurement trial: every 15 minutes over the $7 \mathrm{~h} 30 \mathrm{~min}$ period. Since the lowest of such values may be subject to high error rates, mainly due to the different physiological status of animals prior to the measurement, we defined BMR as a mean of the third, fourth and fifth lowest values, which proved to be quite accurate [76],.

\section{Statistical analyses}

To normalize the data (BMR was right skewed: K-S test, $\mathrm{p}=0.005$ ), body mass, head width and basal metabolic rate measurements were log transformed prior to analyses. Pearson partial correlations between measured characters included sex, population of origin and mtDNA type as cofactors. Repeatabilities $(\tau)$ of traits were estimated on two consecutive measurements (collected between 16 to 51 days; mean $=35.5$ days) as intraclass correlation coefficients, derived either from simple analyses of variance or analyses of covariance with body mass as a continuous predictor [77]. Geographic variation in body mass (BM, g), head width ( $\mathrm{HW}, \mathrm{mm})$ and basal metabolic rate (BMR, $\mathrm{ml} \mathrm{O}_{2} \mathrm{~h}^{-1}$ ) were tested with general linear models. In the models, $\log$ transformed traits (BM, HW and BMR) were included as dependent variables, while sex, type of mtDNA (rutilus vs. glareolus), longitude (2 levels) and latitude (3 levels) of populations were included as fixed independent factors. Analyses were also conducted on residual values of $B M R$, derived from linear regression of $\log$ BMR on $\log$ BM. 


\section{Additional material}

\section{Additional file 1: Table S1 - Primers and PCR parameters for mitochondrial and nuclear markers. \\ Additional file 2: table S2 - Localities, species sampled, and detected haplotypes. \\ Additional file 3: table S3 - GenBank accession numbers for cyt $b$ haplotypes.}

Additional file 4: table S4 - GenBank accession numbers for nuclear haplotypes

Additional file 5: Sequence alignments included in the study.

Additional file 6: figure S1 - Observed (bars) and expected (gray lines) mismatch distributions of Finnish populations of bank voles. a), b) and c) refer to populations of bank voles with native mtDNA type $(G L A) ; d), e)$ and f) Sotkamo population with both mtDNA types and g) and $h$ ) populations of bank voles with red voles mtDNA type (RUT). See Figure 1 for information about localizations of populations. Values of the expansion parameters are only shown if the assumptions of the Sudden Expansion Model are fulfilled.

Additional file 7: figure S2 - Differences in phenotype between populations. Differences in means ( \pm SE) of body mass $(\mathrm{g})$ and basal metabolism (BMR; $\mathrm{mL} \mathrm{O}_{2} \mathrm{~h}^{-1}$ ) between Finnish populations of Myodes glareolus. Data are presented separately for females (circles) and males (triangles) captured along West (filled) and East (open figures) latitudinal gradients.

\section{Acknowledgements}

We gratefully acknowledge Riikka Närä for physiological and Sami Kyröläinen for molecular laboratory efforts, Matti Koivula and Tom Hoogesteger for help in field work, Jackson Jennings and two anonymous Reviewers for their helpful comments on the manuscript and Konnevesi Research Station and the Experimental Animal Unit of the University of Jyväskylä for providing the facilities. The study was financially supported by the Academy of Finland (grant no 115961, 119200, 140767 and 218107 to EK; 09165 and 204284 to TM), the University of Jyväskylä (mobility grant to ZB), the Centre of Excellence in Evolutionary Research of the Academy of Finland and Portuguese Fundação para a Ciência e a Tecnologia, FCT (project grant PTDC/BIA-EVF/111931/2009, partially funded by Fundo Europeu de Desenvolvimento Regional FCOMP-01-0124-FEDER-014266). JM-F is a postdoctoral grantee of the FCT, Portugal (SFRH/BPD/43264/2008; POPHQREN funds from the European Social Fund and Portuguese MCTES). ZB was a Marie Curie Host Fellow (fellow/contract number: 00-00133-18/HPMT-CT2000-00133)

\section{Author details}

${ }^{1}$ Centre of Excellence in Evolutionary Research, Department of Biological and Environmental Science, University of Jyväskylä, P.O. Box 35 YAC, Finland. ${ }^{2} \mathrm{CIBIO}$, Centro de Investigação em Biodiversidade e Recursos Genéticos, Universidade do Porto, Campus Agrário de Vairão, 4485-661 Vairão, Portugal. ${ }^{3}$ Departamento de Biologia, Faculdade de Ciências da Universidade do Porto, Rua do Campo Alegre, s/n, 4169-007 Porto, Portugal. ${ }^{4}$ University of Montana, Wildlife Biology Program, College of Forestry and Conservation, Missoula, MT 59812, USA. ${ }^{5}$ Department of Biological and Environmental Science, University of Jyväskylä, P.O. Box 35 YAC, Finland.

\section{Authors' contributions}

ZB carried out the fieldwork, phenotypic and genetic analyses, and all statistical analyses and drafted the manuscript. EK and TM participated in fieldwork and laboratory studies as well as in designing experiments and drafting the manuscript. SB conducted PCR and sequencing as well as alignment and phase analyses of nuclear markers. PCA and JM-F participated in all analyses of molecular data and in drafting and finalizing the manuscript. All authors read and approved the final version of manuscript.

Received: 23 February 2011 Accepted: 9 December 2011 Published: 9 December 2011

\section{References}

1. Boratyński Z, Koskela E, Mappes M, Oksanen TA: Sex-specific selection on energy metabolism - selection coefficients for winter survival. J Evol Biol 2010, 23(9):1969-1978.

2. Boratyński Z, Koteja P: Sexual and natural selection on body mass and metabolic rates in free-living bank voles. Funct Ecol 2010, 24(6):1252-1261.

3. Boratyński Z, Koteja P: The association between body mass, metabolic rates and survival of bank voles. Funct Ecol 2009, 23(2):330-339.

4. Jackson DM, Trayhurn P, Speakman JR: Associations between energetics and over-winter survival in the short-tailed field vole Microtus agrestis. J Anim Ecol 2001, 70(4):633-640.

5. Sadowska ET, Labocha MK, Baliga K, Stanisz A, Wroblewska AK, Jagusiak W Koteja P: Genetic correlations between basal and maximum metabolic rates in a wild rodent: consequences for evolution of endothermy. Evolution 2005, 59(3):672-681.

6. Larivée ML, Boutin S, Speakman JR, McAdam AG, Humphries MM: Associations between over-winter survival and resting metabolic rate in juvenile North American red squirrels. Funct Ecol 2010, 24(3):597-607.

7. Nilsson J, Åkesson M, Nilsson JF: Heritability of resting metabolic rate in a wild population of blue tits. J Evol Biol 2009, 22(9):1867-1874.

8. Blackmer AL, Mauck RA, Ackerman JT, Huntington CE, Nevitt GA, Williams JB: Exploring individual quality: basal metabolic rate and reproductive performance in storm-petrels. Behav Ecol 2005, 16(5):906-913.

9. Lovegrove BG: The influence of climate on the basal metabolic rate of small mammals: a slow-fast metabolic continuum. J Comp Physiol B 2003, 173(2):87-112.

10. Rezende EL, Bozinovic F, Garland T Jr: Climatic adaptation and the evolution of basal and maximum metabolism in rodents. Evolution 2004, 58(6):1361-1374

11. Ksiąek A, Konarzewski M, Łapo IB: Anatomic and energetic correlates of divergent selection for basal metabolic rate in laboratory mice. Physiol Biochem Zool 2004, 77(6):890-899.

12. Konarzewski M, Diamond J: Evolution of basal metabolic fate and organ masses in laboratory mice. Evolution 1995, 49(6):1239-1248.

13. da Fonseca RR, Johnson WE, O'Brien SJ, Ramos MJ, Agostinho A: The adaptive evolution of the mammalian mitochondrial genome. BMC Genomics 2008, 9(1):119.

14. Dowling DK, Friberg U, Lindell J: Evolutionary implications of non-neutral mitochondrial genetic variation. TREE 2008, 23(10):546-554.

15. Hassanin A, Ropiquet A, Couloux A, Cruaud C: Evolution of the mitochondrial genome in mammals living at high altitude: new insights from a study of the tribe Caprini (Bovidae, Antilopinae). J Mol Evol 2009, 68(4):293-310.

16. Rand DM, Haney RA, Fry AJ: Cytonuclear coevolution: the genomics of cooperation. TREE 2004, 19(12):645-653.

17. Machado CA, Hey J: The causes of phylogenetic conflict in a classic Drosophila species group. Proc R Soc Lond B 2003, 270(1520):1193-1202.

18. Arnold ML: Evolution through genetic exchange Oxford University Press; 2006.

19. Arnold ML: Natural hybridization and evolution Oxford University Press; 1997.

20. Alves PC, Melo-Ferreira J, Freitas H, Boursot P: The ubiquitous mountain hare mitochondria: multiple introgressive hybridization in hares, genus Lepus. Phil Trans R Soc B 2008, 363(1505):2831-2839.

21. Richardson $A O$, Palmer JDJ: Horizontal gene transfer in plants. $J$ Exp Bot 2007, 58(1):1-9.

22. Bachtrog D, Thornton K, Clark A, Andolfatto P: Extensive introgression of mitochondrial DNA relative to nuclear genes in the Drosophila yakuba species group. Evolution 2006, 60(2):292-302.

23. Doi A, Suzuki H, Matsuura ET: Genetic analysis of temperature-dependent transmission of mitochondrial DNA in Drosophila. Heredity 1999, 82(5):555-560.

24. Doiron $S$, Bernatchez $L$, Blier PU: A comparative mitogenomic analysis of the potential adaptive value of arctic charr mtDNA introgression in brook charr populations (Salvelinus fontinalis Mitchill). Mol Biol Evol 2002, 19(11):1902-1909.

25. Ropiquet A, Hassanin A: Hybrid origin of the Pliocene ancestor of wild goats. Mol Phylogenet Evol 2006, 41(2):395-404.

26. Ballard JWO, Melvin RG: Linking the mitochondrial genotype to the organismal phenotype. Mol Ecol 2010, 19(8):1523-1539. 
27. Tegelström H: Transfer of mitochondrial DNA from the northern redbacked vole (Clethrionomys rutilus) to the bank vole (C. glareolus). J Mol Evol 1987, 24(3):218-227.

28. Runck A, Matocq M, Cook J: Historic hybridization and persistence of a novel mito-nuclear combination in red-backed voles (genus Myodes). BMC Evol Biol 2009, 9(1):114.

29. Cook JA, Runck AM, Conroy CJ: Historical biogeography at the crossroads of the northern continents: molecular phylogenetics of red-backed voles (Rodentia: Arvicolinae). Mol Phylogenet Evol 2004, 30(3):767-777.

30. Lebedev VS, Bannikova AA, Tesakov AS, Abramson NI: Molecular phylogeny of the genus Alticola (Cricetidae, Rodentia) as inferred from the sequence of the cytochrome b gene. Zool Scr 2007, 36(6):547-563.

31. Amori G, Hutterer R, Kryštufek B, Yigit N, Mitsain G, Muñoz LJP, Henttonen H, Vohralík V, Zagorodnyuk I, Juškaitis R, Meinig H, Bertolino S: Myodes glareolus 2008 [http://www.iucnredlist.org], IUCN 2010. IUCN Red List of Threatened Species. Version 2010.4..

32. Linzey AV, Henttonen H, Sheftel B, Batsaikhan N: Myodes rutilus 2008 [http:// www.iucnredlist.org], IUCN 2010. IUCN Red List of Threatened Species. Version 2010.4.

33. Deffontaine $\mathrm{V}$, Libois $\mathrm{R}$, Kotlik $\mathrm{P}$, Sommer R, Nieberding C, Paradis $E$, Searle JB, Michaux JR: Beyond the Mediterranean peninsulas: evidence of central European glacial refugia for a temperate forest mammal species, the bank vole (Clethrionomys glareolus). Mol Ecol 2005, 14(6):1727-1739.

34. Abramson N, Rodchenkova E, Fokin M, Rakitin S, Gileva E: Recent and ancient introgression of mitochondrial DNA between the red (Clethrionomys rutilus) and bank (Clethrionomys glareolus) voles (Rodentia, Cricetidae). Dokl Biol Sci 2009, 425(1):147-150.

35. Johns GC, Avise JC: A comparative summary of genetic distances in the vertebrates from the mitochondrial cytochrome b gene. Mol Biol Evol 1998, 15(11):1481-1490

36. Nabholz B, Glémin S, Galtier N: Strong variations of mitochondrial mutation rate across mammals-the longevity hypothesis. Mol Biol Evol 2008, 25(1):120-130.

37. Hudson RR, Kreitman M, Aguade M: A test of neutral molecular evolution based on nucleotide data. Genetics 1987, 116(1):153-159.

38. Rand DM: The units of selection of mitochondrial DNA. Annu Rev Ecol Syst 2001, 32:415-448.

39. Ballard JWO, Whitlock MC: The incomplete natural history of mitochondria. Mol Ecol 2004, 13(4):729-744.

40. Mappes T, Grapputo A, Hakkarainen H, Huhta E, Koskela E, Saunanen R, Suorsa P: Island selection on mammalian life-histories: genetic differentiation in offspring size. BMC Evol Biol 2008, 8(1):296.

41. Bozinovic F, Rojas JM, Broitman BR, Vásquez RA: Basal metabolism is correlated with habitat productivity among populations of degus (Octodon degus). Comp Biochem Physiol A 2009, 152(4):560-564.

42. Tieleman BI, Versteegh MA, Fries A, Helm B, Dingemanse NJ, Gibbs HL, Williams JB: Genetic modulation of energy metabolism in birds through mitochondrial function. Proc R SOC B 2009, 276(1662):1685-1693.

43. Montooth KL, Meiklejohn CD, Abt DN, Rand DM: Mitochondrial-nuclear epistasis affects fitness within species but does not contribute to fixed incompatibilities between species of Drosophila. Evolution 2010, 64(12):3364-3379.

44. Teeter KC, Payseur BA, Harris LW, Bakewell MA, Thibodeau LM, O'Brien JE, Krenz JG, Sans-Fuentes MA, Nachman MW, Tucker PK: Genome-wide patterns of gene flow across a house mouse hybrid zone. Genome Res 2008, 18(1):67-76.

45. Payseur BA, Place M: Searching the genomes of inbred mouse strains for incompatibilities that reproductively isolate their wild relatives. $J$ Hered 2007, 98(2):115-122.

46. Fontanillas P, Depraz A, Giorgi MS, Perrin N: Nonshivering thermogenesis capacity associated to mitochondrial DNA haplotypes and gender in the greater white-toothed shrew, Crocidura russula. Mol Ecol 2005, 14(2):661-670.

47. Speakman JR, Król E, Johnson MS: The functional significance of individual variation in basal metabolic rate. Physiol Biochem Zool 2004, 77(6):900-915.

48. Koteja P: Energy assimilation, parental care and the evolution of endothermy. Proc R Soc Lond B 2000, 267:479-484

49. Farmer CG: Reproduction: the adaptive significance of endothermy. Am Nat 2003, 162(6):826-840

50. Frank SA, Hurst LD: Mitochondria and male disease. Nature 1996 383(6597):224.
51. Currat M, Ruedi M, Petit RJ, Excoffier $L$ : The hidden side of invasions: massive introgression by local genes. Evolution 2008, 62(8):1908-1920.

52. Excoffier L, Foll M, Petit JR: Genetic consequences of range expansions. Annu Rev Ecol Evol Syst 2009, 40(1):481-501.

53. Melo-Ferreira J, Boursot P, Randi EA, Suchentrunk F, Ferrand N, Alves PC: The rise and fall of the mountain hare (Lepus timidus) during Pleistocene glaciations: expansion and retreat with hybridization in the Iberian Peninsula. Mol Ecol 2007, 16(3):605-618.

54. Melo-Ferreira J, Alves PC, Freitas H, Ferrand N, Boursot P: The genomic legacy from the extinct Lepus timidus to the three hare species of Iberia: contrast between mtDNA, sex chromosomes and autosomes. Mol Ecol 2009, 18(12):2643-2658

55. Petit R, Excoffier L: Gene flow and species delimitation. TREE 2009 24:386-393.

56. Chan KMA, Levin SA: Leaky prezygotic isolation and porous genomes: rapid introgression of maternally inherited DNA. Evolution 2005, 59(4):720-729.

57. Bondrup-Nielsen S, Karlsson F: Movements and spatial patterns in populations of Clethrionomys species: a review. Ann Zool Fenn 1983, 22(3):385-392.

58. Nagao Y, Totsuka Y, Atomi Y, Kaneda H, Lindahl KF, Imai H, Yonekawa Y: Decreased physical performance of congenic mice with mismatch between the nuclear and the mitochondrial genome. Genes Genet Syst 1998, 73:21-27

59. Roubertoux PL, Sluyter F, Carlier M, Marcet B, Maarouf-Veray F, Cherif C, Marican C, Arrechi P, Godin F, Jamon M, Verrier B, Cohen-Salmon C: Mitochondrial DNA modifies cognition in interaction with the nuclear genome and age in mice. Nat Genet 2003, 35(1):65-69.

60. Macdonald D, Barrett P: Collins field guide. Mammals of Britain \& Europe Harper Collins; 1993.

61. Stephens M, Smith NJ, Donnelly P: A new statistical method for haplotype reconstruction from population data. Am J Hum Biol 2001, 68(4):978-989.

62. Librado P, Rozas J: DnaSP v5: a software for comprehensive analysis of DNA polymorphism data. Bioinformatics 2009, 25(11):1451-1452.

63. Excoffier L, Laval G, Schneider S: Arlequin (version 3.0): An integrated software packege for population genetics data analysis. Evol Bioinform Online 2005, 1:47-50.

64. Tamura K, Dudley J, Nei M, Kumar S: MEGA4: molecular evolutionary genetics analysis (MEGA) software version 4.0. Mol Biol Evol 2007, 24(8):1596-1599.

65. Posada D, Crandall K: MODELTEST: testing the model of DNA substitution. Bioinformatics 1998, 14(9):817-818.

66. Kosakovsky SL, Pond SD, Frost W, Muse SV: HyPhy: hypothesis testing using phylogenies. Bioinformatics 2005, 21(5):676-679.

67. Felsenstein J: Evolutionary trees from DNA sequences: A maximum likelihood approach. J Mol Evol 1981, 17(6):368-376.

68. Guindon S, Gascuel O: A simple, fast, and accurate algorithm to estimate large phylogenies by maximum likelihood. Syst Biol 2003, 52(5):696-704.

69. Huelsenbeck JP, Ronquist F: MRBAYES: Bayesian inference of phylogenetic trees. Bioinformatics 2001, 17(8):754-755

70. Clement M, Posada D, Crandall KA: TCS: a computer program to estimate gene genealogies. Mol Ecol 2000, 9(10):1657-1659.

71. Rogers AR, Harpending $\mathrm{H}$ : Population growth makes waves in the distribution of pairwise genetic differences. Mol Biol Evol 1992, 9(3):552-569.

72. Schneider S, Excoffier L: Estimation of past demographic parameters from the distribution of pairwise differences when the mutation rates vary among sites: application to human mitochondrial DNA. Genetics 1999, 152(3):1079-1089.

73. Tajima F: Statistical method for testing the neutral mutation hypothesis by DNA polymorphism. Genetics 1989, 123(3):585-595.

74. Fu YX: Statistical tests of neutrality of mutations against population growth, hitchhiking and background selection. Genetics 1997, 147(2):915-925.

75. Koteja P: Measuring energy metabolism with open-flow respirometric systems: which design to choose? Funct Ecol 1996, 10(5):675-677.

76. Labocha MK, Sadowska ET, Baliga K, Semer AK, Koteja P: Individual variation and repeatability of basal metabolism in the bank vole, Clethrionomys glareolus. Proc R Soc Lond B 2004, 271:367-372.

77. Falconer DS, Mackay TFC: Introduction to quantitative genetics Longman, Essex; 1996. 
doi:10.1186/1471-2148-11-355

Cite this article as: Boratyński et al:: Introgression of mitochondrial DNA among Myodes voles: consequences for energetics? BMC Evolutionary Biology 2011 11:355.

Submit your next manuscript to BioMed Central and take full advantage of:

- Convenient online submission

- Thorough peer review

- No space constraints or color figure charges

- Immediate publication on acceptance

- Inclusion in PubMed, CAS, Scopus and Google Scholar

- Research which is freely available for redistribution 